\title{
Control of elevated blood pressure in acute intracerebral hemorrhage
}

\author{
Opeolu Adeoye $e^{1,2}$
}

Addresses: ${ }^{1}$ University of Cincinnati Neuroscience Institute, Departments of Emergency Medicine and Neurosurgery, Division of Neurocritical Care, 231 Albert Sabin Way, ML 0769, Cincinnati, OH 45267-0769, USA; ${ }^{2}$ University of Cincinnati Medical Center, Cincinnati, OH 45267-0525, USA

Email: opeolu.adeoye@uc.edu

Fl000 Medicine Reports 2010, 2:75 (doi:10.3410/M2-75)

This is an open-access article distributed under the terms of the Creative Commons Attribution-Non Commercial License (http://creativecommons.org/licenses/by-nc/3.0/legalcode), which permits unrestricted use, distribution, and reproduction in any medium, provided the original work is properly cited. You may not use this work for commercial purposes.

The electronic version of this article is the complete one and can be found at: http://fl 000.com/reports/m/2/75

\begin{abstract}
Intracerebral hemorrhage remains a challenging worldwide clinical problem with no proven treatments. In the acute phase of the illness, there has been some controversy regarding the appropriate management of elevated blood pressure. Recently published and ongoing clinical trials are beginning to shed some light on appropriate blood pressure management in acute intracerebral hemorrhage. This brief review focuses on these trials. In the next few years, it is hoped that clinical uncertainty regarding this issue will be obviated after completion of these trials.
\end{abstract}

\section{Introduction and context}

Spontaneous intracerebral hemorrhage ( $\mathrm{ICH}$ ) occurs in an estimated 2 million people worldwide each year $[1,2]$. ICH has a 30 -day mortality of $32-50 \%[3,4]$ and only $20 \%$ of survivors are functionally independent at 6 months [5]. No proven therapies exist for ICH. Elevated blood pressure at presentation is one of the factors that has been consistently associated with worse outcomes in ICH [6-8]. It remains unclear whether elevated blood pressure is an epiphenomenon of severe ICH or an independent risk factor for poor outcome. The rate of blood pressure decline in the first 24 hours after ICH has also been associated with poor outcomes [9]. Thus, there is clinical concern that markedly elevated blood pressure may contribute to early hematoma expansion, while overly aggressive blood pressure reduction may compromise cerebral blood flow to perihematomal regions of the brain.

Since phase III clinical trial data are lacking, recent guidelines do not have Class I recommendations for blood pressure reduction in ICH $[3,10]$. The European Stroke Initiative Guidelines recommend a target mean arterial pressure (MAP) of $125 \mathrm{mmHg}$ in patients with a history of hypertension and $110 \mathrm{mmHg}$ in those without a history of hypertension [10]. The American
Heart Association Guidelines recommend keeping MAP at less than $130 \mathrm{mmHg}$ while maintaining cerebral perfusion pressure at more than $60 \mathrm{mmHg}$ in patients with elevated intracranial pressure. A goal MAP of $110 \mathrm{mmHg}$ is recommended for patients without elevated intracranial pressure [3]. This review focuses on recently published and ongoing clinical trials that may directly impact blood pressure management in acute ICH within the next few years.

\section{Recent advances}

The Intensive Blood Pressure Reduction in Acute Cerebral Haemorrhage Trial (INTERACT) is the largest study published to date on blood pressure management in acute ICH [11]. INTERACT enrolled ICH patients diagnosed by computed tomography within 6 hours of symptom onset with elevated systolic blood pressure $(150-220 \mathrm{mmHg})$. A total of 404 patients were randomized to intensive blood pressure reduction (target systolic blood pressure $140 \mathrm{mmHg}$; $\mathrm{n}=203$ ) or standard guideline-based management of blood pressure (target systolic blood pressure $180 \mathrm{mmHg}$; $=201$ ). The primary endpoint was change in hematoma volume at 24 hours. Safety and clinical outcomes were assessed for up to 90 days. 
From randomization to 1 hour, mean systolic blood pressure was $153 \mathrm{mmHg}$ in the intensive group and $167 \mathrm{mmHg}$ in the guideline group $(P<0.0001)$; from 1 hour to 24 hours, it was $146 \mathrm{mmHg}$ in the intensive group and $157 \mathrm{mmHg}$ in the guideline group $(P<0.0001)$. The relative risk of hematoma expansion was 36\% lower (95\% confidence interval $0-59 \%$, $P=0.05)$ in the intensive group than in the guideline group. Intensive blood pressure reduction did not alter the risks of adverse events or outcomes at 90 days. The authors concluded that early blood pressure reduction is clinically feasible, well tolerated, and may reduce hematoma expansion in ICH [11].

The Antihypertensive Treatment of Acute Cerebral Hemorrhage (ATACH) trial is another recently published study of blood pressure management in acute ICH [12]. The objective of ATACH was to determine the safety and feasibility of three levels of systolic blood pressure reduction within 6 hours of symptom onset in ICH patients with initial systolic blood pressure greater than or equal to $170 \mathrm{mmHg}$. Intravenous nicardipine was infused for a target systolic blood pressure of $170-200 \mathrm{mmHg}$ in the first cohort of patients $(\mathrm{n}=18), 140-170 \mathrm{mmHg}$ in the second cohort $(\mathrm{n}=20)$ and $110-140 \mathrm{mmHg}$ in the third cohort $(\mathrm{n}=22)$. Primary outcomes were feasibility of treatment, neurological deterioration within 24 hours, and serious adverse events within 72 hours. No significant adverse events above the pre-specified safety stopping points were observed [12].

\section{Implications for clinical practice}

The INTERACT study provides the best available evidence to date for aggressive early blood pressure reduction in ICH. Overall, INTERACT suggests that for patients similar in clinical characteristics to those enrolled in the study, reducing systolic blood pressure to $140 \mathrm{mmHg}$ is safe and may reduce risk of hematoma expansion. The Second Intensive Blood Pressure Reduction in Acute Cerebral Haemorrhage Trial (INTERACT2) is the phase III follow-up study to INTERACT. An estimated 2800 patients will be enrolled by the planned December 2011 study completion date [13]. This study may provide clinicians with an answer regarding an ageold clinical question in the management of acute ICH. The ATACH investigators are also proceeding with a phase III follow-up study, although recruitment has not begun for that study. It should be noted that INTERACT excluded patients with the severest injury (Glasgow Coma Score [GCS] 3-5), and enrolled patients had mean ICH volumes of $12 \mathrm{~mL}$ (guideline) and $14 \mathrm{~mL}$ (intensive). INTERACT was also not powered to detect clinical outcomes. ATACH included only patients with a GCS of greater than 8 and hematoma volume of less than
$60 \mathrm{~mL}$. Therefore, the findings in these trials may not be applicable to all $\mathrm{ICH}$ patients.

In summary, while many clinical questions remain regarding the acute management of $\mathrm{ICH}$, recent and ongoing trials are shedding light on the management of blood pressure in acute ICH. It is anticipated that Class I recommendations for blood pressure management in ICH will be generated by ongoing trials.

\section{Abbreviations}

ATACH, Antihypertensive Treatment of Acute Cerebral Hemorrhage; GCS, Glagow Coma Score; ICH, intracerebral hemorrhage; INTERACT, Intensive Blood Pressure Reduction in Acute Cerebral Haemorrhage Trial; MAP, mean arterial pressure.

\section{Competing interests}

OA is on the speakers' bureau for EKR Therapeutics.

\section{References}

I. Qureshi AI, Mendelow AD, Hanley DF: Intracerebral haemorrhage. Lancet 2009, 373:1632-44.

FI000 Factor 3.0 Recommended Evaluated by David Archer 09 Jul 2009

2. Lloyd-Jones D, Adams RJ, Brown TM, Carnethon M, Dai S, De Simone G, Ferguson TB, Ford E, Furie K, Gillespie C, Go A, Greenlund K, Haase N, Hailpern S, Ho PM, Howard V, Kissela B, Kittner S, Lackland D, Lisabeth L, Marelli A, McDermott MM, Meigs J, Mozaffarian D, Mussolino M, Nichol G, Roger VL, Rosamond W, Sacco R, Sorlie P, et al.: Heart disease and stroke statistics - 2010 update. A report from the American Heart Association. Circulation 2009, I 2 I:e46-e2 I5.

FI000 Factor 3.0 Recommended

Evaluated by Benedikt Preckel 19 Apr 2010

3. Broderick J, Connolly S, Feldmann E, Hanley D, Kase C, Krieger D, Mayberg M, Morgenstern L, Ogilvy CS, Vespa P, Zuccarello M; American Heart Association/American Stroke Association Stroke Council; American Heart Association/American Stroke Association High Blood Pressure Research Council; Quality of Care and Outcomes in Research Interdisciplinary Working Group: Guidelines for the management of spontaneous intracerebral hemorrhage in adults: 2007 update: a guideline from the American Heart Association/American Stroke Association Stroke Council, High Blood Pressure Research Council, and the Quality of Care and Outcomes in Research Interdisciplinary Working Group. Circulation 2007, I I 6:e39 I-4I3.

4. Flaherty ML, Haverbusch M, Sekar P, Kissela B, Kleindorfer D, Moomaw CJ, Sauerbeck L, Schneider A, Broderick JP, Woo D: Longterm mortality after intracerebral hemorrhage. Neurology 2006, 66: $1182-6$.

5. Fogelholm R, Murros K, Rissanen A, Avikainen S: Long term survival after primary intracerebral haemorrhage: a retrospective population based study. I Neurol Neurosurg Psychiatry 2005, 76: I534-8.

6. Leonardi-Bee J, Bath PM, Phillips SJ, Sandercock PA: Blood pressure and clinical outcomes in the International Stroke Trial. Stroke 2002, 33:1315-20.

7. Vemmos KN, Tsivgoulis G, Spengos K, Zakopoulos N, Synetos A, Manios E, Konstantopoulou P, Mavrikakis M: U-shaped relationship between mortality and admission blood pressure in patients with acute stroke. J Intern Med 2004, 255:257-65. 
8. Leira R, Davalos A, Silva Y, Gil-Peralta A, Tejada J, Garcia M, Castillo J: Early neurologic deterioration in intracerebral hemorrhage: predictors and associated factors. Neurology 2004, 63:46I-7.

9. Qureshi Al, Bliwise DL, Bliwise NG, Akbar MS, Uzen G, Frankel MR: Rate of 24-hour blood pressure decline and mortality after spontaneous intracerebral hemorrhage: a retrospective analysis with a random effects regression model. Crit Care Med 1999, 27:480-5.

10. Steiner T, Kaste M, Forsting M, Mendelow D, Kwiecinski H, Szikora I, Juvela S, Marchel A, Chapot R, Cognard C, Unterberg A, Hacke W: Recommendations for the management of intracranial haemorrhage - part I: spontaneous intracerebral haemorrhage. The European Stroke Initiative Writing Committee and the Writing Committee for the EUSI Executive Committee. Cerebrovasc Dis 2006, 22:294-3I6.

II. Anderson CS, Huang Y, Wang JG, Arima H, Neal B, Peng B, Heeley E, Skulina C, Parsons MW, Kim JS, Tao QL, Li YC, Jiang JD, Tai LW,
Zhang JL, Xu E, Cheng Y, Heritier S, Morgenstern LB, Chalmers J; INTERACT Investigators: Intensive blood pressure reduction in acute cerebral haemorrhage trial (INTERACT): a randomised pilot trial. Lancet Neurol 2008, 7:391-9.

FI000 Factor 6.5 Must Read Evaluated by Luzius A Steiner 14 May 2008, Nicola Latronico 12 Sep 2008, Martin Smith 16 Dec 2008

12. Antihypertensive treatment of acute cerebral hemorrhage. Crit Care Med 2010, 38:637-48.

FI000 Factor 3.0 Recommended

Evaluated by Martin Smith 03 Aug 2010

13. ClinicalTrials.gov - The Second Intensive Blood Pressure Reduction in Acute Cerebral Haemorrhage Trial (INTERACT2). [http://www.clinicaltrials.gov/ct2/show/NCT007/6079? term $=$ Second + Intensive\&rank $=I]$ 